\title{
(Des)envolvimento profissional e atividade: pistas para pensar a formação e o desenvolvimento de competências no serviço público federal
}

\author{
Louise Cordeiro Borba Nogueira ${ }^{1}$, Helder Pordeus Muniz ${ }^{2}$ \\ Universidade Federal Fluminense (Niterói, RJ, Brasil)
}

Neste artigo, pretendemos refletir sobre as ações de formação e desenvolvimento de competências profissionais no contexto do serviço público federal. Para nos auxiliar nesse debate, nos utilizamos das perspectivas de pensar o trabalho como atividade, com base na ergologia, na ergonomia da atividade e na clínica da atividade, no intuito de afirmar que, para (des)envolver pessoas no trabalho, é preciso considerar não só as normas prescritas dele, mas também as estratégias que o próprio trabalhador desenvolve para lidar com os imprevistos que atravessam a situação de trabalho e que, muitas vezes, não são visíveis ou registradas. Acreditamos que desconsiderar a experiência de trabalho nas ações de formação pode gerar equívocos na gestão de políticas de desenvolvimento de pessoas. Como forma de ilustrar nossa discussão, apresentamos o relato de trabalho de formação com grupo de servidores técnico-administrativos de escola federal do Rio de Janeiro, baseado nos dispositivos denominados Encontros sobre o Trabalho.

Palavras-chave: Formação profissional, Desenvolvimento de competências, Ergologia, Serviço público.

Professional development/involvement and activity: clues to think about the formation and development of competencies in the federal civil service

In this article we intend to reflect on the actions concerning education and development of professional competencies in the context of federal civil service. To assist in this discussion, the perspective of labor as activity was used, based on ergology, activity ergonomy, and activity clinic, intending to state that in order to develop/involve people in work is necessary to consider not only its prescribed rules, but also the strategies the worker develops to handle unforeseen work situations that, multiple times, are not seen or registered. We believe that to disregard work experience in educational actions may create errors in people development policies management. To illustrate this discussion we present the education work report of a group of technical-administrative servers of Rio de Janeiro federal school, based on the devices named Meetings about Work.

Keywords: Professional education, Competencies development, Ergology, Civil service.

\section{Introdução}

$\mathrm{E}$ ste artigo tem como principal objetivo suscitar reflexões acerca dos processos de formação profissional e desenvolvimento de competências na interface com as políticas de gestão e administração de pessoal, vigentes no contexto do serviço público federal. Não pretendemos questionar, aqui, o fato de que a qualidade de prestação de serviços no setor público precisa ser melhorada em muitos aspectos e que ela deva ser tema de debates, mas sim a que custo essas mudanças no gerenciamento do trabalho vêm acontecendo, principalmente para os trabalhadores.

A Política Nacional de Desenvolvimento de Pessoas (PNDP), documento que atravessa nosso debate e é representado pelo Decreto no 5.707, de 23 de fevereiro de 2006, aposta no modelo de gestão por competências e ações de capacitação para seus trabalhadores como principal ferramenta de mudança do serviço público (Carvalho et al., 2009). Entretanto, queremos pensar sobre até que ponto esses "novos métodos de gestão"3 podem ser potencializadores e sobre até onde eles podem ser armadilha para esse trabalhador, uma vez que o discurso de "valorização" e

1 Psicóloga do trabalho da Universidade Federal Fluminense (UFF). Mestre em Psicologia pela UFF e doutoranda do Programa de Pós-Graduação em Psicologia do Instituto de Psicologia da UFF.

2 Professor do Programa de Pós-Graduação em Psicologia do Instituto de Psicologia da Universidade Federal Fluminense.

3 Preferiríamos chamá-los de "métodos de gerenciamento", já que na perspectiva ergológica todo trabalhador faz gestão do trabalho, e não apenas os chefes ou gerentes. 
"valoração" deles pode, dependendo do olhar que está impresso sobre o trabalho, causar equívocos em sua gestão. Questionamos o modo como a PNDP e a Escola Nacional de Administração Pública (Enap) fazem uso do modelo de competências e das ações de capacitação, correndo o risco de individualizar e despotencializar a atividade de trabalho ao valorizar apenas estratégias de "formação-consumo" (Heckert, \& Neves, 2007, p. 4) como ferramenta. Por formação-consumo entende-se formação que valoriza pacotes de conteúdos para ser prontamente aplicados, muitas vezes desarticulados do cotidiano dos trabalhadores.

Pretendemos, neste artigo, apontar para um desenvolvimento de pessoas que não é linear e programado e que não ocorre desarticulado das situações reais de trabalho, mas que remete a um (des) envolvimento, entendendo que ele só ocorre na medida em que envolvemos as pessoas como agentes ativas na gestão do trabalho. É importante esclarecer que, quando afirmamos envolvimento, não nos referimos a motivação pessoal, mas à importância de levarmos em conta também o ponto de vista e a experiência daquele que trabalha - não como ponto de vista individualizado e relativizado, mas inserido em processo político-coletivo. Caso contrário, acreditamos que essas práticas e métodos de gerenciamento podem, na verdade, ocasionar não envolvimento do trabalhador com sua atividade de trabalho.

Assim, nosso interesse em pensar a formação e o desenvolvimento no serviço público federal emerge na tentativa de problematizar e colocar em debate gerenciamento do trabalho e práticas de formação que acabam por não envolver os trabalhadores. Para nos auxiliar nesse debate, utilizaremos autores da ergologia e das clínicas do trabalho, que partem de olhar diferenciado sobre a atividade de trabalho para pensar outros modos de se construírem dispositivos de formação profissional.

Para ilustrar nosso tema serão apresentados alguns elementos de ação de formação com os trabalhadores de uma escola federal do Rio de Janeiro realizada no ano de 2009.

\section{Pistas teóricas e metodológicas}

Para darmos prosseguimento a essa discussão, é imperativo problematizar as transformações nos mundos do trabalho e a tese de que, custe o que custar, o setor público deve se adaptar a elas. De acordo com o material produzido pela Enap, adaptar o serviço público a "novo contexto de mudanças globais... e à emergência de novos cenários para o mundo do trabalho" tem sido a palavra de ordem da administração pública federal para promover mudanças nas relações de trabalho e desenvolver estratégias para a "adoção de novos perfis de competências profissionais" (Antonello, $\&$ Pantoja, 2010, p. 51). Tendo isso em vista, queremos apontar para outro posicionamento ante esses "novos métodos de gestão", importados, em sua grande parte, de experiências na esfera do gerenciamento privado. Nossa intenção com essa discussão é alertar os agentes de formação das instituições públicas de que é preciso confrontar essas transformações e se colocar além do simples julgamento acerca de quem se adapta ou não a elas.

Nesse sentido, partindo das contribuições da ergologia, pretendemos imprimir outra perspectiva de análise dos impactos que essas transformações trazem às relações de trabalho e às práticas de "capacitação" e "desenvolvimento de pessoas" no serviço público federal. Ao problematizar as mudanças no mundo e no trabalho, consideramos que essas modificações não atingem de forma automática e igualitária todas as pessoas, e que seria necessária análise mais específica acerca de como essas mudanças são apreendidas pelos trabalhadores, para não corrermos o risco de julgar de forma simplista aqueles que se adaptam ou não. Sobre essa questão, Schwartz (2010a) nos alerta:

essas formas de abordar as mudanças do trabalho são ambas unilaterais e de todo modo elas colocam entre parênteses as situações reais de trabalho, as situações reais de atividade. Não há, creio eu, 
julgamento único. Se não se faz um esforço de ir ver de perto como cada um não apenas "se submete" - entre aspas - mas vive e tenta recriar sua situação de trabalho, se não se faz esse esforço, então interpreta-se, julga-se e diagnostica-se no lugar das próprias pessoas e isso não pode produzir resultados positivos (p. 26).

Dessa forma, antes de problematizarmos os dispositivos atuais de formação profissional, é necessário que se entenda como eles se configuraram ao longo da história. É importante entendermos os debates e as transformações do sistema capitalista e a maneira como ocorre a transição da necessidade de treinamento de trabalhadores para a adaptação ao posto de trabalho - funcionamento característico dos modos de produção tayloristas/fordistas - à urgência em desenvolver competências, em que o saber-fazer do trabalhador e sua capacidade de iniciativa e inovação tornam-se o mote do funcionamento das políticas de administração/gestão de pessoas no contemporâneo, cujo foco passa a ser a produção de bens de prestação de serviços (Zarifian, 2010).

Com base nessa discussão, é possível perceber os reflexos dessas políticas de "administração de pessoas" no setor público. No Brasil, embora a necessidade de administrar os trabalhadores date de 1930 com a criação da Consolidação das Leis do Trabalho (CLT), é a partir de 1996 que podemos começar a ver indícios da abordagem das competências, quando esse termo surge pela primeira vez na Lei de Diretrizes e Bases da Educação, intrinsecamente ligado às questões de formação profissional e, de acordo com a PNDP, que data de 2006, é o modelo que passa a vigorar na administração de pessoas no setor público federal.

Entrar em contato com as apostilas e os cadernos produzidos pela Enap (Carvalho et al., 2009; Pires et al., 2005) foi de extrema importância para entendermos como o Governo Federal vem implementando o modelo de gestão por competências. Embora o discurso fosse de valorização do saber-fazer do trabalhador, não conseguíamos entender em que o modelo de competências se diferenciava do antigo modelo de posto de trabalho, marca forte do taylorismo, no qual as ações de capacitação e treinamento serviam justamente para adaptar os trabalhadores às exigências do cargo. Um dos nossos maiores desconfortos acerca desses materiais está no modo como são trazidas as definições de competências: por trechos retirados de autores, ipsis litteris, recortados e descontextualizados, nos quais é predominante a tendência da abordagem anglo-saxônica das competências, de matriz condutivista/behaviorista. Essa abordagem nos apresenta conceito de competências pautado na perspectiva do "desempenho superior", como "estoque de qualificações" relacionadas a inteligência e personalidade e passíveis de avaliação, sendo, portanto, "apenas um rótulo mais moderno para administrar uma realidade organizacional ainda fundada nos princípios do taylorismo-fordismo" (Fleury, \& Fleury, 2001, p. 185).

Entretanto, o material da Enap apresenta também alguns recortes de autores ligados à abordagem francofônica, entre eles principalmente as citações de Phillipe Zarifian (2010) e Guy Le Boterf $(1998,2008)$. Esses autores - que para nós aproximam-se das discussões que a ergologia nos apresenta e que pretendemos afirmar - criticam o conceito anglo-saxônico das competências como uma "carteira de perfis" estanque, uma vez que a abordagem francofônica aponta para complexidade das situações de trabalho - e para sinergia entre as competências (que a organização exige) e as competências (mobilizadas pelos trabalhadores no coletivo). Desse modo, a utilização de forma misturada e pouco discutida das vertentes anglo-saxônica e francofônica sobre as competências, a nosso ver contraditórias, nos causou estranhamento, principalmente porque o conceito apresentado no Decreto no 5707/06 privilegia a abordagem anglo-saxônica (caracterizada no segundo artigo do documento como "conhecimentos, habilidades e atitudes") para a implementação do modelo de gestão e desenvolvimento de pessoas na administração pública.

Considerando isso, entendemos que é preciso problematizar o modo como as publicações da Enap foram confeccionadas, pois, embora elas ainda datem do ano em que o decreto foi 
elaborado - em 2016, dez anos após sua publicação -, ainda não se tem notícias sobre a revisão desses conceitos. Portanto, elas ainda servem de material de consulta em diversas ações para os servidores federais que atuam com desenvolvimento de trabalhadores, e, até mesmo, de tentativa de padronização dos processos de trabalho.

Portanto, para que déssemos maior consistência à nossa discussão, foi fundamental entender o modo como alguns dos principais autores utilizados pela Enap expõem esses e outros conceitos acerca da definição de competências, no sentido de não apenas reproduzir fragmentos prontos, mas também de conhecer desdobramentos e implicações de cada um e pensar outros possíveis na construção de ações de formação no serviço público federal.

Phillipe Zarifian (2010) é o mais citado entre os autores da abordagem francofônica das competências. A leitura de seus textos esclareceu nossas dúvidas e reafirmou nossas críticas acerca do modo como o modelo de competências estava sendo implementado no setor público federal. Assim como aponta esse autor, percebemos que a leitura que o governo federal vem fazendo do modelo de competências é apenas versão modernizada do modelo de posto de trabalho taylorista. Portanto, essa política corre o risco de, em vez de (des)envolver as competências dos trabalhadores, preocupar-se somente em gerenciar seu desempenho, restringindo as competências à utilização de "fórmulas" prontas para ser aplicadas e de comportamentos observáveis, desconsiderando assim toda a complexidade da atividade de trabalho e os saberes produzidos, na medida em que o imprevisto acontece.

As publicações da Enap (Carvalho et al., 2009; Pires et al., 2005), ao citarem Zarifian, definem competência desta maneira: que o trabalhador saiba "tomar iniciativa e assumir responsabilidades" diante de situações laborais complexas e lidar com o inédito em eventos ou situações de trabalho. Acreditamos que restringir toda a discussão que esse autor traz em seus livros para essa única frase empobrece o conceito de competências e o modo como as organizações podem fazer uso dele. Zarifian (n.d.) nos apresenta importante questão para pensar o modelo de gestão por competências. Ele diz que é preciso entender que há dois pontos de vista coexistentes sobre a definição, mas que eles em momento algum podem se confundir: a diferença entre gerência pela competência (aqui a competência é no singular) e gerenciar as competências (aqui competências, no plural).

De acordo com o autor, "gerência pela competência" remete ao gerenciamento das estratégias de ação organizacionais que permitem pôr em prática o desenvolvimento das competências, com o objetivo de prestar serviço ou obter performance desejada (política ou modelo da competência). Nesse aspecto, Zarifian afirma que a "competência" (no singular) para a organização se define como o resultado de ação que se põe em prática na forma de tomada de iniciativa, de responsabilidade do indivíduo em dada situação de trabalho.

Por outro lado, "gerenciar as competências" trata da gerência do desenvolvimento e da mobilização das "competências" (no plural) do trabalhador e do coletivo de trabalhadores, tendo não só a preocupação de desenvolver e fornecer a competência (no singular) necessária à política de gestão da organização, mas também a preocupação de contemplar as aspirações individuais dos trabalhadores, suas perspectivas, seu engajamento e seu papel social dentro da organização, assim como o sentido que os trabalhadores dão ao seu trabalho.

Todo esse processo envolveria a combinação de três importantes elementos: autonomia, iniciativa e responsabilidade (Zarifian, 2010), de modo que a interação entre eles diante de situações de trabalho complexas e inéditas estabeleça as condições para que haja mobilização e desenvolvimento de competências tanto individuais quanto coletivas.

Para Zarifian, a autonomia condiciona e solicita a mobilização das competências, uma vez que elas se manifestam, justamente, nos espaços de indeterminação, ou seja, espaços nos quais o trabalhador deve agir por si mesmo em situações em que o prescrito não dá conta. Ao agir, o trabalhador toma iniciativa, o que não é ação qualquer, impensada, mas envolve uma série de 
reflexões acerca de sua atividade, de seu engajamento em relação às regras da organização e de seu ofício (também é agir coletivo) e seus possíveis efeitos (Zarifian, 2010).

Finalmente, essa mobilização envolve um "assumir responsabilidade" que não se remete a moral, mas a ética profissional. "Assumir responsabilidade" é "responder por", no sentido de assumir a tomada de iniciativa em situação determinada e inédita, que é atravessada pela construção de conhecimentos ou de patrimônio (a partir do desenvolvimento no e através do coletivo) acerca de sua atividade profissional.

A reflexão coletiva sobre o trabalho é um dos aspectos cruciais que afirmamos para pensar a formação e o (des)envolvimento de competências, aliada à construção de espaços em que a dimensão do acontecimento como criação de possíveis seja considerada. Nesse sentido, a noção de evento (événement) que Zarifian (2010) apresenta é extremamente importante, pois aquilo que é inédito e imprevisível nas situações de trabalho é componente imprescindível para o (des) envolvimento e a formação no trabalho.

Assim como Zarifian, a leitura de alguns textos de Le Boterf foi importante para entendermos a complexidade do modelo de competências. Ele é citado no material da Enap como o autor que fala das "competências coletivas". Embora não haja muito desenvolvimento sobre esse conceito nas publicações da Enap, ao pesquisarmos vimos que, assim como Zarifian, Le Boterf não considera a "competência" como simples soma de recursos e saberes estanques, mas como processo de "combinatórias" entre os diversos saberes que se modificam de acordo com o modo como são "combinados" e mobilizados em determinada situação de trabalho (Le Boterf, 2008). Segundo o autor, de nada adianta que o trabalhador obtenha conhecimentos e técnicas (saberes, saber-fazer, saber-ser), se ele não souber mobilizar seus conhecimentos em situação de trabalho inédita e oportuna (Le Boterf, 1998).

O processo da gestão das competências seria, então, composto por três fatores: o saber agir, que supõe esses saberes combinados e mobilizados, o querer agir, que trata da "motivação e do engajamento pessoal do indivíduo” (Le Boterf, 1998, p. 150, tradução livre) e o poder agir, que se refere à existência de condições organizacionais e sociais que possibilitem o desenvolvimento das competências. É nessa discussão que Le Boterf traz o conceito de "competências coletivas", que não é a soma das competências individuais - embora, segundo o autor, elas componham o seio das competências de uma equipe ou de uma rede - mas, sim, da sinergia entre elas. Assim, em nossa discussão buscamos aproximar esses dois autores (Zarifian e Le Boterf) e as contribuições de Yves Schwartz e da ergologia, por entendermos que eles podem conversar e nos dar subsídios para pensarmos a formação e o (des)envolvimento das competências de trabalhadores no serviço público federal.

Ao pensar o trabalho - ou melhor, as situações de trabalho - como atividade, ou seja, como espaço que é atravessado pelas dimensões do mutável e do instável, a ergologia considera que esses aspectos são fundamentais no processo de desenvolvimento. Portanto, ao olharmos o trabalho na perspectiva ergológica, entendemos que a noção de competência como algo que possa ser julgado e avaliado - assim como a criação de uma definição para ela - pode empobrecer aquilo que a atividade de trabalho tem de transformador (Schwartz, 2010b). Para Schwartz (1998; 2010b), a determinação das competências para o trabalho se apresenta em meio a paradoxo, pois, ao mesmo tempo que é exercício necessário se pensar sobre o que é requerido/desenvolvido no trabalho e se compreender o que uma pessoa faz, essa é questão que se apresenta como "insolúvel", uma vez que a atividade não permite, segundo ele, nenhum julgamento unilateral sobre ela.

A partir dessa discussão, apontamos a necessidade de se pensarem dispositivos de formação e desenvolvimento de competências de trabalhadores no serviço público federal que considerem, também, o sujeito em ação - porque os cursos que apenas capacitam e instrumentalizam os trabalhadores não são suficientes para desenvolvê-las, uma vez que dão conta, parcialmente, 
daquilo que o trabalhador realmente faz. Além disso, fica caracterizado que o coletivo de trabalho é de extrema importância para o desenvolvimento de competências, já que é em meio a ele que o trabalhador pode mobilizá-las, pois - como afirma Schwartz (1998, 2010b, 2010c) - os coletivos não são equipes estáveis, mas complexos dinâmicos e relativamente pertinentes que se agenciam de acordo com a situação de trabalho, visto que ninguém é competente da mesma maneira.

Com base nessas contribuições, apresentaremos o encontro que realizamos com trabalhadores de uma escola federal como forma de ilustrar a discussão anterior e dar pistas aos agentes de formação e gestão de pessoas da administração pública para pensar outras possibilidades sobre os processos de formação de trabalhadores e o (des)envolvimento das competências no serviço público federal.

\section{Uma experiência de formação com “assistentes de alunos": reconstrução da demanda}

O encontro de assistentes de alunos foi planejado com base em consulta feita aos diretores das unidades que compõem a escola, utilizando questionário que tinha o objetivo de relacionar as necessidades de capacitação dos servidores técnico-administrativos. O cargo de "assistente de alunos" é um dos numerosos cargos que compõem o Plano de Cargos e Carreiras dos Técnicos Administrativos em Educação (PCCTAE), documento que rege todos os cargos existentes em todas as instituições federais de ensino do país, criado com base na Lei Federal no 11.091, de 12 de junho de 2005.

De acordo com as atribuições descritas para esse cargo, o "assistente de alunos" deve atuar na disciplina dos alunos e zelar pela sua integridade nas atividades escolares e de lazer e pela integridade do patrimônio da escola, assim como prestar assistência às atividades pedagógicas e administrativas referentes à rotina escolar. A demanda inicial para "capacitar" os servidores que atuavam como assistentes de alunos visava à padronização do trabalho entre as diferentes unidades da escola, além de promover melhor relacionamento desses trabalhadores com alunos, pais e professores. Havia ainda a necessidade de "amenizar" a insatisfação dos trabalhadores por atuarem nesse cargo de "assistente de alunos". Tal insatisfação era notória, uma vez que na época do curso a escola contava com quantitativo bem reduzido de trabalhadores que ocupavam esse cargo - e, em razão da necessidade de se suprirem as dificuldades de organização das rotinas escolares, muitos trabalhadores que haviam feito concurso para o cargo de assistente em administração também realizavam a atividade de assistente de alunos.

A partir daí, surgiram algumas questões: um curso de relações interpessoais que indicasse modos de agir e de se comportar seria suficiente para dar conta da complexidade desse contexto? $\mathrm{O}$ que era esperado de um assistente de alunos nessa escola? $\mathrm{O}$ que eles realmente faziam no seu dia a dia? Qual era o olhar sobre esse cargo e essa atividade, que a tornava tão desvalorizada nessa escola? Como aproveitar esse espaço de formação que estava se abrindo para envolver os trabalhadores nesse processo?

Percebemos que a demanda inicial do curso considerava os trabalhadores como foco do "problema", e isso nos preocupava, porque poderia resultar na legitimação de discurso culpabilizante ou vitimizante em relação a eles. Portanto, era necessário voltar nossas atenções para as situações de trabalho e para a atividade de "atuar na disciplina" dos alunos.

Na busca de reconstrução da demanda foi proposto, então, outro caminho: em vez de focarmos em como eles deveriam agir e se comportar, nós buscaríamos, segundo o modo como eles vinham experimentando essa função, a construção de estratégias que possibilitassem desenvolvimento

4 Antigamente denominado inspetor ou bedel.

\section{6}


da atividade de "atuar na disciplina dos alunos". Nossa tentativa foi a de criar espaço em que não só fosse possível trazer as normas que circulam naquele estabelecimento escolar (ou seja, leis, regimentos escolares, técnicas e atribuições referentes ao cargo, relações de hierarquia entre colegas etc.), mas também fazer que os trabalhadores falassem sobre suas próprias estratégias desenvolvidas em meio à situação de trabalho, trazendo à tona e colocando em debate todas as interferências e as forças que atravessavam o cotidiano deles naquela escola.

Todo o processo de planejamento, elaboração e execução desse encontro de formação com os assistentes de alunos nos fez pensar sobre outras possibilidades de intervenção no trabalho e, também, refletir sobre a possibilidade da construção de propostas de formação que viabilizassem espaço em que fosse possível fazer circularem os saberes da experiência, (des)envolvendo o trabalhador em gestão coletiva do trabalho, não o formando para que vislumbrasse apenas a aplicação de técnicas que visam à modificação de comportamentos.

Para isso, foi preciso que nosso olhar sobre o trabalho se modificasse. A nosso ver, trabalhar não é, somente, aplicar técnicas ou cumprir conjunto de atribuições previamente determinadas. Para intervir no trabalho ou pensar a construção de dispositivos de formação profissional, seria preciso entender o "trabalhar" como uma gestão das variabilidades, ou seja, seria preciso entender que trabalhar é gerir aquilo que rompe com o habitual - e que nesse processo estão envolvidos, também, aspectos muitas vezes invisíveis à gerência, que não estão limitados a lista de comportamentos observáveis.

Era preciso, portanto, que olhássemos o trabalho do ponto de vista da atividade, ou seja, que estivéssemos atentos para aquilo que na situação de trabalho foge ao prescrito, exigindo que o trabalhador se ponha por inteiro na situação (intelectual, biológica e culturalmente) - mobilizando, como Schwartz (2010b, 2014) aponta, uso do "corpo-si" para lidar com esses imprevistos ${ }^{5}$. O aprendizado das técnicas antecipa, parcialmente, o trabalho; entretanto, ao tomarmos o trabalho como atividade, é preciso ter a noção de que ele também é constituído por algo enigmático e que, portanto, não é possível antecipar; além disso, é preciso desenvolver estratégias para lidar com o "inantecipável", o imprevisto, o que só é possível se formos ver de perto como as pessoas trabalham, construindo espaços em que a experiência dos trabalhadores seja formadora.

Nesse sentido, demos preferência ao uso do termo "formação" em contraposição aos termos "capacitação" e "treinamento", termos amplamente utilizados não só pela PNDP, mas principalmente na literatura da área de recursos humanos. A formação, para nós, envolve justamente aquilo que é variável no meio, que produz realidades e não ocorre separado da criação de modos de gestão do trabalho. A capacitação e o treinamento, ao contrário, restringem-se a eventos de aprendizagem de curta duração, com conteúdos e objetivos previamente determinados, pautados por aquilo que o posto de trabalho ou o cargo exige (Carvalho et al., 2009), e não leva em consideração o debate que o trabalhador enfrenta para criar e recriar seus modos de trabalhar. A seguir, faremos breve descrição de como aconteceu o encontro com os trabalhadores dessa escola, de modo a ilustrar e trazer elementos para refletirmos sobre outros modos de formação profissional.

\section{O encontro com os assistentes de alunos: formação de grupos de ação}

Nós não somos inspetores... Essa palavra para mim é horrível, me faz lembrar aquele cara (levanta o dedo indicador) que fica "inspetando" os alunos, dizendo o que se deve ou não

5 A expressão "uso do corpo-si" tem sido fundamental nas discussões de Yves Schwartz. Para o autor, o corpo-si transgride as fronteiras entre o histórico e o biológico, é onde o enigmático da atividade atua e a partir dele se realiza (Schwartz, 2014). 
fazer. Eu acho que fazemos muito mais do que isso... (fala de um trabalhador durante o encontro de assistentes de alunos, 2009).

Inicialmente nos reunimos com grupos diferentes de trabalhadores, divididos da seguinte maneira: unidades escolares I (UEs I), que atuavam com o primeiro segmento do ensino fundamental, e unidades escolares II e III (UEs II e III), segundo segmento e ensino médio. O encontro teve a duração de oito dias (quatro dias para as UEs I e quatro dias para as UEs II e III), com módulos na parte da manhã - cujo conteúdo deveria abordar os aspectos de "motivação e relacionamento interpessoal" - e na parte da tarde - cujo conteúdo deveria abordar aspectos relacionados ao Estatuto da Criança e do Adolescente.

É importante destacar que os trabalhadores, além de lidar com a diferença de faixa etária dos alunos dessa escola federal, tinham atribuições diferentes de acordo com as características das UEs I e das UEs II e III. Nas UEs I, os trabalhadores acumulavam a função de assistentes de alunos com outras funções, realizadas em diferentes setores da escola, como secretaria escolar, reprografia, orientação educacional, biblioteca etc. Quando chegavam os horários de entrada, saída, recreio e idas dos alunos ao banheiro, eles deveriam deixar seus respectivos "postos de trabalho" para dar assistência às crianças. Já nas unidades II e III, os assistentes ficavam somente no "corredor", como eles costumam dizer; ou seja, ficavam somente com a função da "inspeção" propriamente dita: inspecionar entrada, saída, recreios e intervalos dos alunos e dar suporte ao quadro docente da escola (verificação e transporte de material, anotação de recados etc.).

Com relação ao módulo de "relações interpessoais", que teve seu nome modificado para "formação de grupos de ação", sabíamos que poderia haver resistência por parte dos trabalhadores, uma vez que, em razão da problemática que se configurava em torno dessa função na escola, foi estabelecido pelas diretorias que os trabalhadores seriam obrigados a comparecer ao curso; caso contrário, receberiam falta de "não comparecimento ao trabalho".

Procuramos esclarecer de imediato como os encontros ocorreriam. Explicamos que todo o trabalho seria pautado na experiência, na prática deles como assistentes de alunos, propiciando espaço para discussão acerca das impressões pessoais do trabalho naquela escola. Iniciamos o primeiro dia de encontro com uma atividade na qual foi solicitado aos grupos - quatro grupos de UEs I e sete grupos de UEs II e III - que escolhessem uma situação rotineira de trabalho de que gostassem (de fácil solução, agradável etc.) e uma que eles achassem difícil, que "emperrava" o andamento do trabalho. Enfatizamos que qualquer situação poderia ser escolhida, não importando seu grau de complexidade. Quando os grupos chegassem a consenso, deveriam representar a situação para os outros participantes, pois assim poderíamos perceber como os "atores" e as "figuras" na escola eram interpretados na visão de cada grupo. Caso os grupos não se sentissem à vontade para a representação, poderiam fazer apenas uma descrição da situação. Três grupos das unidades I fizeram uma representação, e os outros optaram por uma apresentação descritiva.

Os grupos das unidades I trouxeram para o debate situações com o mesmo tema: a dificuldade de lidar com os alunos com algum tipo de deficiência cognitiva. Com base nas representações, foi possível perceber a angústia dos trabalhadores por se sentirem impotentes ante uma criança que mobilizava toda a unidade. Ao serem questionados sobre o porquê desse sentimento, eles falaram sobre o modo como essas crianças eram inseridas na escola, não havendo nenhum tipo de comunicado por parte da diretoria ou da seção de orientação educacional (pedagogos e psicólogos) que os informasse a respeito de como lidar com aquela situação. A partir dessa discussão, outras situações de trabalho foram sendo apresentadas como "difíceis" na opinião desses trabalhadores: a exigência de que eles ficassem na substituição de professores faltosos, principalmente nas aulas de educação física; o procedimento diante de pais que não vão buscar os filhos na escola - um ponto que levava, consequentemente, à dificuldade de acesso aos pais e à participação em reuniões de pais e mestres e conselhos de classe. 
Por sua vez, os assistentes de alunos das UEs II e III decidiram somente relatar as situações. Mais uma vez, as "queixas" eram similares entre as unidades, mas no caso delas as dificuldades estavam relacionadas à tarefa de "dar falta aos professores" e ao encaminhamento de alunos que os procuravam para confidenciar problemas pessoais - ao setor de orientação educacional. Os assistentes relataram que dar falta e acusar impontualidade de um professor causavam muita insatisfação aos docentes, já que eles responsabilizavam os assistentes de alunos quando as faltas eram descontadas em contracheque. Eles acreditavam que essa função deveria ser do coordenador de disciplina (professor responsável de cada disciplina) ou do próprio diretor da unidade, a quem os professores se remetem. Tanto as unidades I quanto as unidades II e III relataram que o que tornava o trabalho prazeroso eram o reconhecimento e a amizade dos alunos.

A partir dessa dinâmica inicial, começamos a pontuar, com os trabalhadores, aquilo que fazia que a atividade de "atuar na disciplina” fosse tão desvalorizada, não só por eles, mas também pela instituição. Entretanto, ao mesmo tempo foi possível dar início ao debate sobre aquilo que eles faziam e sobre o que mais poderia ser feito para resolver essas e outras questões. Já de início, pudemos perceber quantas competências relativas às atividades de cuidado e reorganização desse coletivo de assistentes precisavam receber mais atenção pelo grupo que ali estava. Nesse sentido, no segundo dia de encontro entregamos aos participantes um texto escrito por um assistente de aluno de outra escola federal, que relacionava algumas questões sobre a função desse profissional ao longo da história das políticas educacionais no Brasil e demonstrava que deveria haver proposta de formação e "capacitação" para essa atividade, uma vez que eles também exerciam o papel de educadores. Além disso, o autor listava série de "competências profissionais" que os assistentes/ inspetores deveriam ter para exercer essa profissão.

Pedimos que os trabalhadores formassem grupos de leitura e discutissem suas impressões sobre o texto, escolhendo relator que relacionasse os pontos que acreditassem pertinentes para o debate. Houve diferenças no debate entre as unidades: para os trabalhadores das UEs I houve insatisfação generalizada, pois eles entenderam, com base no texto, que deveriam fazer mais do que já faziam. Ao mesmo tempo, concordavam com a necessidade de mais informações que lhes dessem subsídios para lidar com estudantes do primeiro segmento do ensino fundamental.

Para os trabalhadores das unidades II e III, a discussão girou em torno da necessidade de busca de "identidade" - segundo eles, enfatizando a importância de se lotarem trabalhadores nessa função que tivessem "perfil" adequado para exercê-la, além da necessidade de formação inicial para esse cargo. Nessa discussão, foi pedido que eles elencassem essas noções de "identidade" e "perfil" e que, embora existissem pessoas que tivessem mais afinidades de trabalhar com essa função, despessoalizassem o cargo e visassem o trabalho que estava sendo feito, apesar de todas as dificuldades encontradas.

Assim, no terceiro dia propusemos a dinâmica chamada "Olha como eu faço", na qual os servidores deveriam listar tudo o que eles fazem, diariamente, desde o momento em que entram na unidade até o momento de saída. Nossa ideia foi aproveitar esse espaço de encontro entre as unidades - que quase nunca acontecia - para possibilitar a partilha de informações sobre as situações de trabalho que já vínhamos debatendo nos dias anteriores, sobre como cada unidade conseguiu solucionar alguns problemas e como soluções novas poderiam surgir da conversa entre eles.

Tal dinâmica foi baseada no método de autoconfrontação da "instrução ao sósia", de Ivar Oddone (Magnier, 1999; Muniz, Brito, Souza, Athayde, \& Lacomblez, 2013), no qual há narrativa para um outro (sósia), que poderia vir a tomar o seu lugar sem que ninguém notasse. Esse método faz que a instrução não seja apenas descrição do que o trabalhador faz, em vez disso exigindo que ele apresente o "como" se faz, como ele desenvolve estratégias para dar conta dos impasses mais íntimos da atividade. 
Embora tenhamos feito modificação desse método em razão do tamanho do grupo e do curto espaço de tempo que tínhamos para discussão aprofundada, a dinâmica mostrou-se extremamente rica, pois foi possível que houvesse partilha, entre os trabalhadores, de dimensões de sua atividade que iam além das prescrições. Apenas com a simples descrição de "o que" eles fazem, com base nos questionamentos apresentados por nós, pelos agentes de formação em questão e pelos pares, foi possível que eles percebessem que havia uma série de atividades que não apareciam nas atribuições definidas pelo PCCTAE. Por exemplo: a simples tarefa de "verificar a entrada de alunos" envolvia todo um debate de normas (inspeção de uniforme, inspeção de caderneta, verificação de atrasos dos alunos etc.) e valores (quantos atrasos um determinado aluno tinha? Dar uma falta prejudicaria aquele determinado aluno? Aquele era um caso que poderia ser resolvido pelo assistente, ou o aluno deveria ser encaminhado à direção? Etc.).

Além disso, essas normas não eram muito bem definidas pela direção da escola e variavam de unidade para unidade, sendo necessário, portanto, estabelecer com os trabalhadores um plano de trabalho em conjunto para cada unidade, aliado à experiência das tarefas a serem exercidas. $\mathrm{Ou}$ seja, essa dinâmica foi importante para que os trabalhadores percebessem como eles faziam "uso" do seu trabalho, em vez de "executarem", simplesmente, uma tarefa que era complexa, embora não parecesse ser. Buscamos, com essa dinâmica, ressaltar o modo como cada um experimentava o trabalho, valorizando as estratégias utilizadas e as parcerias encontradas para enfrentar as dificuldades de "atuar na disciplina". Também foi interessante perceber quanto eles se sentiram satisfeitos em poder falar de "o que" eles fazem e de "como" eles fazem, mediante a troca de ideias entre os colegas das outras unidades escolares, assim como houve reposicionamento dos trabalhadores em relação ao cargo de assistente de alunos, pois muitos se sentiam desvalorizados perante os outros trabalhadores do colégio.

Por fim, no quarto e último dia apresentamos para os participantes a metodologia que utilizamos com base nos encontros sobre o trabalho (Durrive, 2010) e na ergoformação (Durrive, 2011; Durrive, \& Jacques, 2010), levando, em linguagem acessível, os autores que nos auxiliaram para pensar aquele encontro. Procuramos debater com eles quanto era feito para que o atendimento e a assistência aos alunos fossem cumpridos, mesmo que eles não tivessem os subsídios teóricos para tal.

Em seguida, o grupo foi dividido em subgrupos, aleatoriamente, e distribuíram-se trechos do livro Pedagogia da autonomia, de Paulo Freire (2006), que remetiam à prática do educador e do seu cotidiano. Cada grupo deveria debater o trecho recebido e depois apresentar para todos aquilo que foi discutido, ficando livre a escolha de usar exemplos ou comentários pessoais. Ao longo da leitura dos trechos do livro, os grupos problematizaram as situações cotidianas do trabalho na escola e, a partir de algumas delas, refletimos acerca dos valores pessoais e sociais inseridos na prática do dia a dia.

Com base nessa experiência e nos afetos que nos atravessaram na condução desse encontro, percebemos a potência de proporcionar espaço em que o "saber-fazer e o fazer-saber" dos trabalhadores circulassem para produzir o (des)envolvimento no e para o trabalho. Nossa intenção não foi a de apresentar receita de "como fazer" para construir um dispositivo de formação, pois assim contrariaríamos tudo o que viemos discutindo até aqui. No entanto, queríamos chamar a atenção para a necessidade de voltarmos nosso olhar para a atividade e tentar perceber quais pistas os autores da perspectiva ergológica e das clínicas do trabalho nos dão para pensarmos outros modos de se desenvolver e se formar no trabalho.

Entre essas pistas, damos destaque à retomada que alguns autores fazem a Vigotsky e a Ivar Oddone. Com a retomada que Yves Clot $(2007,2010)$ faz de Oddone, percebemos que, para que haja desenvolvimento do coletivo de trabalhadores, é preciso que se constituam espaços de formação em que os trabalhadores estejam no papel de atores, e o psicólogo, ou formador, 
se coloque em posição de coanálise das situações de trabalho. Ele apresenta os saberes formais (científicos ou acadêmicos) de modo a dar subsídios aos trabalhadores para que eles próprios possam debater sua própria experiência e, assim, ser capazes de desenvolver as estratégias e as competências necessárias para seu trabalho.

Além de Oddone, entendemos que as contribuições de Vigotsky (2007) são importantes, porque com ele podemos afirmar que todas as pessoas, independentemente da idade, podem aprender. Para isso, nós, agentes de formação, precisamos estar atentos à "zona" que fica entre aquilo que é composto pelo aprendizado que o trabalhador já traz em sua "bagagem" de vida e pelo aprendizado que ainda está por vir e que poderá ser desenvolvido em meio a coletivo.

No caso dessa escola federal, os estudos sobre os trabalhos desenvolvidos pelo autor soviético podem ser extremamente úteis, dada a heterogeneidade dos participantes dos cursos em relação à idade e à escolaridade. Acreditamos que com a contribuição de Vigotsky podemos pensar que o posicionamento do formador em relação a essa heterogeneidade não deve ser de resistência, como temos visto em nosso dia a dia, mas sim de ferramenta no desenvolvimento potencial dos trabalhadores.

Para finalizar, Faïta (2010) e todos os outros autores que nos auxiliaram nessa discussão enfatizam a importância da linguagem para o desenvolvimento dos trabalhadores, uma vez que é por meio dela que os trabalhadores podem reorganizar os conhecimentos adquiridos na ação, expressando a defasagem entre aquilo que deve ser feito e o que realmente é feito. É pela linguagem que é possível formalizar a experiência. Portanto, defendemos a ideia de que, para viabilizar o desenvolvimento de competências, é preciso que haja a constituição de espaços onde os trabalhadores possam falar sobre sua atividade.

\section{Conclusão}

O artigo em questão pretendeu propor discussão sobre a formação e o desenvolvimento de competências no serviço público federal, de modo a contribuir para a problematização que ainda parece incipiente desde a publicação do Decreto no 5707/06, que instituiu a PNDP na administração pública federal.

Nossa intenção neste texto - mais do que trazer fórmula de pronta-entrega para confecção de cursos de capacitação - foi discutir o modo como a política de formação dos servidores técnicoadministrativos vem se procedendo e colocar em debate a maneira como o governo vem pensando e implementando o modelo de gestão por competências no serviço público federal. Nesse sentido, acreditamos que seja de extrema importância trazer os autores da ergologia e das clínicas do trabalho para essa discussão, com o intuito de ampliar nossos referenciais para pensar ações de formação que também levem em conta o ponto de vista do trabalho como atividade.

Entendemos que nossa experiência de formação com os assistentes de alunos teve limitações teóricas e práticas - por exemplo, o grande número de participantes, que acabou tornando difícil o manejo das discussões e dos debates que surgiam em alguns momentos, uma vez que o espaço para o debate era curto para tantas demandas. Além disso, as questões institucionais que interferiam nos encaminhamentos de algumas falas e decisões do grupo não puderam ser trabalhadas com os participantes, de modo que a perspectiva da ergoformação nos provocava. Entretanto, percebemos que ali foi possível uma abertura para que os trabalhadores pudessem falar sobre o modo como eles estavam se apropriando do fazer de "assistentes de alunos" e compartilhar suas experiências, pensando com os pares outros modos de gerir seu trabalho.

Ao mesmo tempo, percebemos que para construir espaços onde essa troca seja possível é preciso, primeiramente, convencer os gerentes da importância de se olhar diferentemente sobre o 
trabalho e sobre a formação. Caso contrário, podemos correr o risco de frustrar os trabalhadores que se engajaram na construção desse espaço de (des)envolvimento. Ainda assim, acreditamos que o serviço público federal, com suas especificidades de relações de trabalho, diferentes da esfera privada, pode compor campo fértil para se pensarem outros modos de intervir no trabalho que viabilizem gestão ativa e coletiva dos trabalhadores.

\section{Referências}

Antonello, C. S., \& Pantoja, M. J. (2010). Aprendizagem e o desenvolvimento de competências. In M. R. S. Camões, M. J. Pantoja, \& S. T. Bergue (Orgs.), Gestão de pessoas: bases teóricas e experiências no setor público (pp. 51-101). Brasília: Enap.

Carvalho, A. I. D., Vieira, A. S., Bruno, F., Motta, J. I. J., Baroni, M., MacDowell, M. C., Salgado, R., \& Côrtes, S. D. C. (2009). Escolas de governo e gestão por competências: mesa-redonda de pesquisa-ação. Brasília: Enap.

Clot, Y. (2007). A função psicológica do trabalho. Petrópolis, RJ: Vozes.

Clot, Y. (2010). Trabalho e poder de agir. Belo Horizonte: Fabrefactum.

Decreto n. 5.707. (2006, 23 de fevereiro). Institui a política e as diretrizes para o desenvolvimento de pessoal da administração pública federal direta, autárquica e fundacional, e regulamenta dispositivos da Lei n. 8.112, de 11 de dezembro de 1990. Brasília, DF: Casa Civil.

Durrive, L. (2010). Pistas para o ergoformador animar os encontros sobre o trabalho. In Y. Schwartz, \& L. Durrive (Orgs.), Trabalho e ergologia: conversas sobre a atividade humana (2aㅡ ed., pp. 309-318). Niterói: EdUFF.

Durrive, L. (2011). A atividade humana, simultaneamente intelectual e vital: esclarecimentos complementares de Pierre Pastré e Yves Schwartz. Trabalho, Educação e Saúde, 9 (supl. 1), 47-67.

Durrive, L., \& Jacques, A. (2010). O formador ergológico ou ergoformador: uma introdução à ergoformação. In Y.

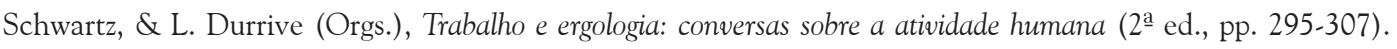
Niterói: EdUFF.

Faïta, D. (2010). A linguagem como atividade. In Y. Schwartz, \& L. Durrive (Orgs.), Trabalho e ergologia: conversas sobre a atividade humana (2ª ed., pp. 189-204). Niterói: EdUFF.

Fleury, M. T. L., \& Fleury, A. (2001). Construindo o conceito de competência. Revista de Administração Contemporânea, 5 (esp.), 183-196.

Freire, P. (2006). Pedagogia da autonomia: saberes necessários à prática educativa. São Paulo: Paz e Terra.

Heckert, A. L. C., \& Neves, C. A. B. (2007). Modos de formar e modos de intervir: quando a formação se faz potência de produção de coletivo. In R. Pinheiro, M. E. B. Barros, \& R. A. Mattos (Org.), Trabalho em equipe sob o eixo da integralidade: valores, saberes e práticas (pp. 145-160). Rio de Janeiro: IMS, UERJ.

Le Boterf, G. (1998). Evaluer les compétences: quels jugements? Quels critères? Quelles instances? Education permanente, 2 (135), 143-152.

Le Boterf, G. (2008). Repenser la compétence. Paris: Eyrolles.

Lein. 11.091. (2005, 12 de junho). Dispõe sobre a estruturação do Plano de Carreira dos Cargos Técnico-Administrativos em Educação, no âmbito das Instituições Federais de Ensino vinculadas ao Ministério da Educação, e dá outras providências. Brasília, DF: Casa Civil.

Magnier, G. (1999). Le travailleur et son double. Les Territoires du Travail, 3, 33-42.

Muniz, H. P., Brito, J., Souza, K. R., Athayde, M., \& Lacomblez, M. (2013). Ivar Oddone e sua contribuição para o campo da Saúde do Trabalhador no Brasil. Revista Brasileira de Saúde Ocupacional, 38 (128), 280-291.

Pires, A. K., Prata, C. F., Santos, D. M., Brandão, H. P., Moraes, H., Carvalho, I. M., Monteiro, J. C., Dias, J. C., Esselin Filho, J. V., Oliveira, M. M. S., Marques, M. I. C., Amaral, P. A., Araújo, P. B. C., Hashimoto, R., Machado, S. S., \& Dantas, V. C. (2005). Gestão por competências em organizações de governo: mesa-redonda de pesquisa-ação. Brasília: Enap. 
Schwartz, Y. (1998). Os ingredientes da competência: um exercício necessário para uma questão insolúvel. Educação \&̊ Sociedade, 19 (65), 101-140.

Schwartz, Y. (2010a). Trabalho e ergologia. In Y. Schwartz, \& L. Durrive (Orgs.), Trabalho e ergologia: conversas sobre a atividade humana (2ª ed., pp. 25-36). Niterói: EdUFF.

Schwartz, Y. (2010b). Uso de si e competência. In Y. Schwartz, \& L. Durrive (Orgs.), Trabalho e ergologia: conversas sobre a atividade humana (2ae ed., pp. 205-221). Niterói: EdUFF.

Schwartz, Y. (2010c). A dimensão coletiva do trabalho e as entidades coletivas relativamente pertinentes (ECRP). In Y. Schwartz, \& L. Durrive (Orgs.), Trabalho e ergologia: conversas sobre a atividade humana (2aㅡ. ed., pp. 149-164). Niterói: EdUFF.

Schwartz, Y. (2014). Motivações do conceito de corpo-si: corpo-si, atividade, experiência. Letras de Hoje, 49 (3), 259. 274.

Vigotski, L. S. (2007). A formação social da mente: o desenvolvimento dos processos psicológicos superiores. São Paulo: Martins Fontes.

Zarifian, P. (n.d.). Manager par la competence, manager les competences. Recuperado de http://philippe.zarifian.pagespersoorange.fr/page63.htm [14 dezembro 2016]

Zarifian, P. (2010). O modelo da competência: trajetória histórica, desafios atuais e propostas. In M. S. Salerno (Org.), O modelo da competência: trajetória histórica, desafios atuais e propostas. São Paulo: Senac.

\section{Endereço para correspondência}

louiseborba@id.uff.br, heldermuniz@uol.com.br 